\title{
The Study of the Electrospark Coating Effect on the Heat Removal Property of Hard Alloy
}

\author{
Yaroslav A. Vostrikov*a and Sardana A. Sleptsova ${ }^{b}$ \\ ${ }^{a}$ Far Eastern State Transport University \\ Khabarovsk, Russian Federation \\ ${ }^{b}$ M.K. Ammosov North-Eastern Federal University \\ Yakutsk, Russian Federation
}

Received 05.12.2019, received in revised form 21.01.2020, accepted 07.02.2020

\begin{abstract}
The effect of a protective coating on the heat removal properties of a cutting plate made of VK8 tungsten-containing hard alloy has been studied. The article provides a sequence of measurements made by a thermal imager and a thermograph to install a mechanism for heat removal by a protective coating. The factors affecting the fault in temperature measurements in a static experiment by means of a thermal imager are described. The time to maximum temperature transferred from the heated counterbody to the hard alloy with and without coating has been obtained. The exposure time of the maximum temperature transmitted from the counterbody to the alloys under study has been fixed. It has been demonstrated that a multilayer electrospark coating based on $\mathrm{Ni}, \mathrm{Cu}, \mathrm{Fe}, \mathrm{Cr}, \mathrm{W}$ reduces the maximum temperature under the same test conditions by $42 \%$, while the surface cooling rate at the point close to the cutting edge increases by $53 \%$. The data obtained show the effect of the protective coating on the heat removal property of the hard alloy. The time of heat propagation over the entire surface of the test sample and the cooling time have been studied by means of a thermograph. There is a temperature difference of $103^{\circ} \mathrm{C}$ for the alloy without coating that has been calculated simultaneously between the points on the cutting edge and at a distance of $2 \mathrm{~mm}$ lower along the front surface, while for the alloy with a protective coating the difference was $79^{\circ} \mathrm{C}$, it is less by $24 \%$. The thermograms of alloys with and without coating are clearly shown at time to maximum temperature on the surface. The work of the coating to remove heat from the point of contact with the heated counterbody has been proven, and the heat removal property is explained by the composition of the coating obtained by electrospark alloying with electrodes based on $\mathrm{Cu}, \mathrm{Ni}, \mathrm{Fe}, \mathrm{W}$, and $\mathrm{Cr}$.
\end{abstract}

Keywords: hard alloy, electrospark alloying, multilayer coating, heat sink, thermogram, thermal imager.

Citation: Vostrikov Ya.A., Sleptsova S.A. The study of the electrospark coating effect on the heat removal property of hard alloy, J. Sib. Fed. Univ. Eng. \& Technol., 2020, 13(2), 133-143. DOI: 10.17516/1999-494X-0209

(C) Siberian Federal University. All rights reserved

This work is licensed under a Creative Commons Attribution-NonCommercial 4.0 International License (CC BY-NC 4.0).

* Corresponding author E-mail address: Ya-vostrikov@mail.ru, ssard@yandex.ru 


\title{
Исследование влияния электроискрового покрытия на теплоотводящее свойство твердого сплава
}

\author{
Я.А. Востриков ${ }^{a}$, С.А. Слепцова ${ }^{0}$ \\ а Дальневосточный государственный университет \\ путей сообщения \\ Российская Федераџия, Хабаровск \\ ${ }^{6}$ Северо-Восточный федеральный университет \\ им. М.К. Аммосова \\ Российская Федерация, Якутск
}

Аннотация. В работе выполнены исследования влияния защитного покрытия на теплоотводящие свойства режущей пластины из вольфрамсодержащего твердого сплава марки ВК8. В статье приведена последовательность измерений температуры тепловизором и термографом для установления механизма отвода тепла защитным покрытием. Описаны факторы, влияющие на погрешность измерений температуры в статичном эксперименте при помощи тепловизора. Получено время достижения максимума температуры, передаваемой от нагретого контртела твердому сплаву с покрытием и без покрытия. Установлена длительность выдержки максимальной температуры, передаваемой от контртела к исследуемым сплавам. Показано, что многослойное электроискровое покрытие на основе $\mathrm{Ni}, \mathrm{Cu}, \mathrm{Fe}, \mathrm{Cr}, \mathrm{W}$ снижает значение максимальной температуры при одинаковых условиях испытаний на 42 \%, при этом скорость остывания поверхности в точке, близкой к режущей кромке, увеличилась на 53 \%. Полученные данные показывают влияние защитного покрытия на теплоотводящее свойство твердого сплава. Исследования времени распространения тепла по всей поверхности образца, а также время остывания проводили на термографе. Установлена разница в $103{ }^{\circ} \mathrm{C}$ у сплава без покрытия, в одно и то же время, между точками на режущей кромке и на расстоянии 2 мм ниже по передней поверхности, при этом для сплава с защитным покрытием такая разница составила $79{ }^{\circ} \mathrm{C}$, что на 24 \% ниже. Наглядно показаны термограммы сплавов с покрытием и без в момент времени достижения максимального значения температуры на их поверхности. Работа покрытия по отведению тепла из точки контакта с нагретым контртелом доказана в ходе исследований, а теплоотводящее свойство объясняется составом покрытия, полученного электроискровым легированием электродами на основе $\mathrm{Cu}, \mathrm{Ni}, \mathrm{Fe}, \mathrm{W}$, и $\mathrm{Cr}$.

Ключевые слова: твердый сплав, электроискровое легирование, многослойное покрытие, теплоотвод, термограмма, тепловизор.

Цитирование: Востриков, Я.А. Исследование влияния электроискрового покрытия на теплоотводящее свойство твердого сплава / Я.А. Востриков, С.А. Слепцова // Журн. Сиб. федер. ун-та. Техника и технологии, 2020. 13(2). С. 133 143. DOI: $10.17516 / 1999-494 X-0209$

\section{Введение}

В машиностроении, металлообработке, горном деле и других отраслях народного хозяйства наибольшее распространение в качестве режущих инструментов получили вольфрамсодержащие твердые сплавы (ВТС). Твердые сплавы на основе карбида вольфрама и карбида титана обладают уникальными физико-механическими свойствами, что делает их привлекательными для использования в качестве инструментального материала для обработки резанием [1]. Однако при высоких скоростях резания в области контакта инструмента с обрабатываемой деталью температура твердого сплава может достигать более $800{ }^{\circ} \mathrm{C}$, что приводит к сниже- 
нию его твердости и износостойкости и, как следствие, к уменьшению периода стойкости [2]. Период стойкости режущего инструмента при обработке полимерных материалов зависит от разных факторов, в том числе от стойкости к износу и стойкости к химическому окислению на воздухе [3]. Анализ литературы показал, что значения температур в зоне резания превышают допустимые. Например, для твердого сплава ВК8 допустимые значения температуры в зоне резания равны $700-750{ }^{\circ} \mathrm{C}$, однако температура в процессе резания полимерных материалов достигает $900-1100^{\circ} \mathrm{C}[4]$. В связи с этим необходимо создать условие для отвода температуры из зоны резания и ограничения доступа кислорода к основе твердого сплава, тем самым повысить жаростойкость вольфрамсодержащего твердого сплава. В данной работе это предлагается осуществить за счет создания материала на поверхности твердого сплава.

\section{Методика}

Для исследования теплопроводности твердых сплавов использовали переносной тепловизор марки Flir i3 и портативный компьютерный термограф ИРТИС - 2000. Тепловизор способен без расшифровки данных показать распределение тепловых полей, однако точность границ тепловых полей низкая из-за большого количества окружающих факторов. При помощи тепловизора определяли механизм распределения тепла между твердым сплавом с защитным покрытием и нагретым контртелом. Точку измерения значений температуры выбирали на доступном для чувствительности прибора расстоянии, равном 5 мм от места контакта с контртелом. В ходе исследования проводили многократное измерение температуры в нескольких точках, затем рассчитывали среднее значение, которое использовалось в дальнейшем. В результате установления материалов, влияющих на теплопроводность твердых сплавов, и механизма этого теплоотвода при помощи тепловизора требовалось уточнение зависимости температуры от времени и зависимости температуры и расстояния от места контакта с нагретым контртелом. Для уточнения этих зависимостей использовали термограф. Схематичное расположение исследуемого образца, контртела и измерительного прибора показано на рис. 1.

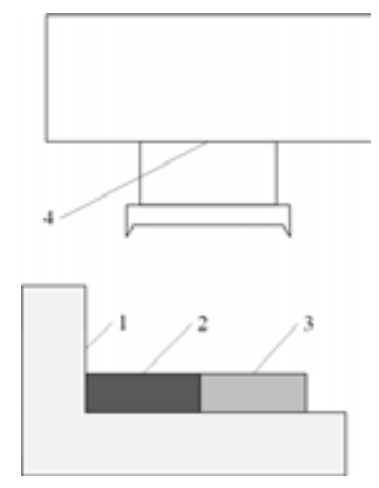

Рис. 1. Схематичное представление эксперимента по исследованию отвода тепла с поверхности твердого сплава при контакте с нагретым контртелом, вид сбоку: 1 - асбестовая подложка; 2 - нагретое контртело; 3 - исследуемый образец (твердый сплав ВК8); 4 - измерительный прибор (тепловизор или термограф)

Fig. 1. Schematic representation of an experiment to study the removal of heat from the surface of a hard alloy in contact with a heated counterbody, side view: 1 - asbestos substrate; 2 - heated counterbody; 3 - test sample (VK8 hard alloy); 4 - measuring device (thermal imager or thermograph) 
Исследования, проводимые при помощи термографа, состоят из двух этапов. Первый этап - предварительные исследования. Второй - модельные исследования.

Предварительные исследования проводили для контроля равномерной передачи тепловой энергии и выявления факторов, влияющих на ее отклонение в момент контакта твердого сплава и нагретого контртела. Многократным проведением предварительных исследований установлено влияние различных факторов на погрешность в колебаниях температуры, при которой результаты исследований искажаются и вызывают сомнения. К факторам, влияющим на колебания температур, относится окалина контртела, неустойчивое положение твердого сплава и контртела, перегрев подложки, на которой находился материал, и др. Если колебания температур в разных точках измерения превышали разницу в $2 \%$ от средней температуры контртела в момент контакта с твердым сплавом, то эксперимент повторяли с устранением факторов, влияющих на эти колебания. Таким образом достигалась равномерная, относительно одинаковая передача тепла на всей поверхности контакта между контртелом и твердым сплавом во всех экспериментах.

При проведении исследования в качестве подложки под нагретые материалы использовали асбестовую плиту и огнеупорные кирпичи для минимизации потери тепла в окружающую среду и установления теплообмена преимущественно между контртелом и твердым сплавом. После каждого эксперимента температуру подложки доводили до значения комнатной путем охлаждения в воде.

Исследуемым материалом выбран твердый сплав ВК8, нагреваемым контртелом - сталь 45. Подготовка поверхности образцов к исследованию включала в себя очищение материалов от загрязнений и шлифовку их поверхности в месте контакта. Эксперимент проводили в статичной форме, то есть теплопередача от контртела к образцу не поддерживалась, а имела естественный ход. Цель такого эксперимента - сравнить количественные данные влияния электроискрового покрытия на теплоотводящее свойство твердого сплава. Для проведения исследований контртело разогревали в муфельной печи до температуры $850^{\circ} \mathrm{C}$, затем прикладывали его к твердому сплаву. Максимальная температура нагретого контртела составляла $815^{\circ} \mathrm{C}$, в точках контакта контртела с твердым сплавом максимальная температура равнялась $751{ }^{\circ} \mathrm{C}$.

Для получения электроискрового покрытия использовали анодные электродные материалы - медь $(\mathrm{Cu})$ и никель $(\mathrm{Ni})$ с теплопроводностью выше, чем у основы, твердостью ниже, чем у электрода, формирующего верхний защитный слой. Такие материалы способствуют формированию подслоя и выполняют роль промежуточного слоя, релаксирующего внутренние напряжения покрытия [1]. Формировали многослойное покрытие на сменных многогранных твердосплавных пластинах токарных резцов электродами из технической меди, никеля и белого чугуна, легированного хромом и вольфрамом (табл. 1).

Покрытие на пластинах формировалось по передней поверхности, по задней поверхности и задней вспомогательной поверхности. Работы по формированию износостойкого покрытия проводили на установке Элитрон 14«а» согласно «инструкции по упрочнению режущих инструментов» от 31.08.1990. Свойства изделий с покрытиями соответствовали требованиям ГОСТ 3882-74 «Сплавы твердые спеченные» и требованиям ГОСТ Р 50-28-87 «Рекомендации формы заточки режущей части резцов для обработки пластмасс и условий их эксплуатации». Покрытие на твердом сплаве формировали от режущей кромки до середины передней 
Таблица 1. Выбранные электродные материалы

Table 1. Selected electrode materials

\begin{tabular}{|l|l|}
\hline \multicolumn{1}{|c|}{ Название } & \multicolumn{1}{c|}{ Химический состав, масс. \% } \\
\hline $\mathrm{BK} 8$ & $\mathrm{~W}=86.4, \mathrm{Co}=8.1, \mathrm{C}=5.65, \mathrm{O}_{2} \leq 0.5, \mathrm{Fe} \leq 0.3$ \\
\hline $\mathrm{Ni}$ (сплав) & $\mathrm{Ni}=99.8, \mathrm{Co} \leq 0.15, \mathrm{C}=0.02, \mathrm{Si}=0.002, \mathrm{~S}=0.0003, \mathrm{Fe}=0.04$ \\
\hline $\mathrm{Cu}$ (сплав) & $\mathrm{Cu}=99.90, \mathrm{O}=0.05, \mathrm{Fe}=0.005, \mathrm{~Pb}=0.005, \mathrm{~S}=0.005, \mathrm{Zn}=0.005$ \\
\hline Легированный чугун & $\mathrm{W}=7.5, \mathrm{Cr}=3.7 ; \mathrm{C}=4.3 ; \mathrm{Mn}=0.6 ; \mathrm{S}=0.4 ; \mathrm{P}=0.3 ; \mathrm{Si}=1.1 ; \mathrm{Fe}=$ ост. \\
\hline
\end{tabular}

Таблица 2. Нумерация сплавов с защитными покрытиями

Table 2. The numbering of the alloys with protective coatings

\begin{tabular}{|c|c|c|c|}
\hline Номер & Пояснение & Марка основы & $\begin{array}{c}\text { Порядок формирования слоев от } \\
\text { твердого сплава к поверхности }\end{array}$ \\
\hline Сплав 1 & Исходный сплав & Вольфрамсодержащий & Без покрытия \\
\cline { 1 - 1 } Сплав 2 & Сплав с покрытием & твердый сплав BК8 & $\mathrm{BK} 8-\mathrm{Cu}-\mathrm{Ni}-$ Легированный чугун \\
\hline
\end{tabular}

поверхности (расстояние выбирали произвольно, но одно и то же для всех электродов). Для удобства интерпретации результатов, приведенных далее, твердым сплавам были присвоены порядковые номера (табл. 2).

\section{Результаты}

Исследование механизма распределения температуры по поверхности твердого сплава с покрытием и без покрытия, при контакте с нагретым контртелом проводили с использованием тепловизора, результаты представлены на рис. 2.

Исследование механизма теплоотвода из зоны контакта твердого сплава и контртела включает в себя определение момента времени достижения максимальной температуры на поверхности твердого сплава, определение длительности нагрева по времени, определение времени выдержки максимальной температуры в точке измерения на поверхности твердого сплава, определение времени начала снижения температуры. Наиболее вероятно, что теплоотвод в основу твердого сплава или в атмосферу осложнен несколькими факторами: однородностью твердого сплава, то есть его теплопроводность одинакова по всей площади; удаленностью очага нагрева от места контакта твердого сплава с материалами, имеющими отличную от твердого сплава теплопроводность, что не позволяет своевременно отводить температуру из зоны резания при обработке полимерных материалов.

Анализ приведенного графика (рис. 2б) показал, что независимо от наличия покрытия, у всех сплавов время достижения максимальной температуры в выбранной точке составляет 62 секунды. Установленная зависимость температуры от времени для сплава 2 показывает, что в начальный момент времени, с 1-й по 3-ю с, температура возрастает на $60 \%$ от общей максимальной со скоростью $20{ }^{\circ} \mathrm{C}$ в секунду, затем темп роста замедляется, составляет $1{ }^{\circ} \mathrm{C}$ в секунду и далее уменьшается до начала остывания.

$$
-137-
$$




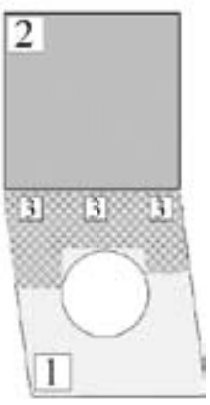

a)

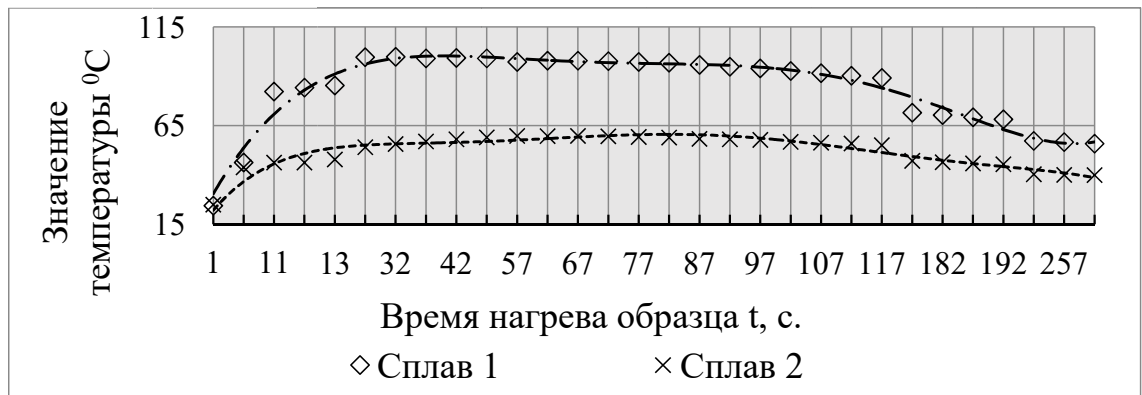

б)

Рис. 2. Исследование тепловизором распределения тепла по поверхности сплава ВК8: а - схематичное изображение точек измерения температуры, вид сверху: 1 - твердый сплав, 2 - нагретое контртело, 3 точка измерения температуры; б - график распределения тепла по поверхности сплава ВК8 при контакте с нагретым контртелом

Fig. 2. Study of the heat distribution on the surface of the VK8 alloy with a thermal imager: a - a schematic representation of temperature measurement points, top view: 1 - hard alloy, 2 - heated counterbody, 3 - temperature measurement point; 6 - graph of heat distribution over the surface of VK8 alloy in contact with a heated counterbody

В приведенном графике для сплава 1 максимум температуры за 62 с достигает $103,45{ }^{\circ} \mathrm{C}$. Максимальная температура (нагрев от 99 до $103,45^{\circ} \mathrm{C}$ и остывание от $103,45{ }^{\circ} \mathrm{C}$ до $99{ }^{\circ} \mathrm{C}$ ) держится с 32-й по 92-ю с. Таким образом, выдержка твердого плава без покрытия составляет 1 мин. Снижение температуры начинается с 97-й с и далее продолжает снижаться до комнатной температуры. Однако для сплава 2 максимум температуры за 62 с достигает $59,8{ }^{\circ} \mathrm{C}$, это на 42 \% меньше по сравнению со сплавом 1 при одинаковых условиях нагрева. В таком случае отмечается работа покрытия у сплава 2 по механизму отвода тепла в основу, на это указывает снижение температуры поверхности твердого сплава.

Для определения разности температур между точкой измерения на границе контакта контртела и твердого сплава и самой дальней измеряемой точкой проводили исследования термографом (рис. 3). Результаты этого измерения позволяют уточнить механизм теплоотвода покрытия на твердом сплаве по сравнению со сплавом без покрытия.

Результаты измерений температуры в каждом из четырех рядов сравнивали друг с другом для определения значения колебания температур по всей исследуемой поверхности. Установлено, что в четырех рядах максимальные колебания температур не превышали $2 \%$, разница в температурах между каждой точкой одного сплава составляла $0,2-0,4 \%$. В связи с этим в дальнейшей работе использовали средние значения температур из четырех вертикальных рядов в точках P1 - Р6 для каждого исследуемого сплава.

Однако в данном исследовании точка P1 не учитывалась, так как на распространение температуры через эту точку влияло контртело, а не основа твердого сплава. Для исследования распределения температуры через основу твердого сплава с покрытием и без покрытия сравнивали точку Р2 и нижнюю точку Р6. На рис. $3 a$ представлено схематическое изображение точек измерения температуры на поверхности твердого сплава. Начальная точка P1 расположена на расстоянии 0,28 мм от края сплава. Расстояние между каждой точкой от Р1 до Р6 установлено экспериментально и составляет 2 мм. Точки Р2 - Р5 использовали для 


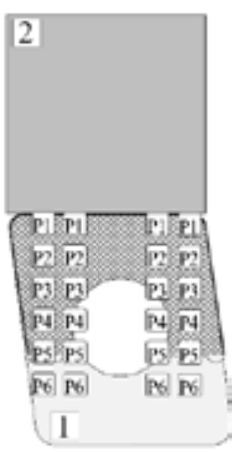

a)

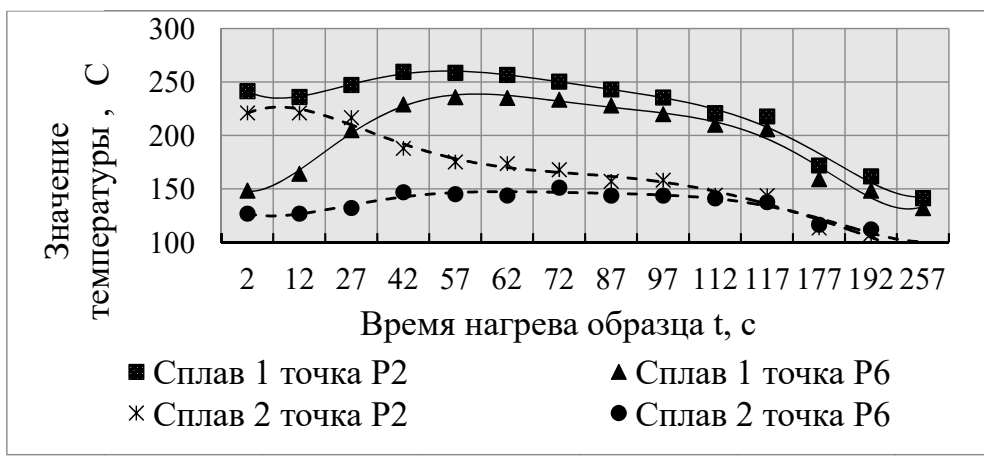

б)

Рис. 3. Исследование термографом распределения тепла по поверхности сплава ВК8: а - схематичное изображение точек измерения температуры, вид сверху: 1 - твердый сплав, 2 - нагретое контртело, P1-P6 - точки измерения температуры; б - изменение температуры от времени между точкой измерения P2 и нижней точкой Р6

Fig. 3. Thermograph study of heat distribution over the surface of VK8 alloy: a - a schematic representation of temperature measuring points, top view: 1 - hard alloy, 2 - heated counterbody, P1-P6 - temperature measuring points; $\sigma$ - temperature change over time between the measuring point P2 and the lower point P6

установления скорости нагрева поверхности в определенное время и подтверждения работы покрытия в виде отвода тепла внутрь твердого сплава (в этих точках значение температуры ниже, чем на сплаве без покрытия). Точка Р6 находится на незащищенной поверхности твердого сплава, ниже покрытия. Измерение температуры в этой точке показало влияние покрытия на скорость распространения температуры от времени по сравнению с этой точкой на твердом сплаве без покрытия.

Приведенный график (рис. 3б) демонстрирует время нагрева твердого сплава в точке Р2 и Р6 и момент начала снижения температуры в этих точках. Это время отражает скорость нагрева до достижения максимальной температуры и ее дальнейшего снижения. Анализ данных сплава 1 показал, что максимальная температура на поверхности в точке Р2 достигала $256{ }^{\circ} \mathrm{C}$ за 42 с и сохранялась до 57 с, а в точке Р6 максимум температуры в $225{ }^{\circ} \mathrm{C}$ наблюдался только на 57-й с. Таким образом, для прохождения максимума температуры через режущую кромку и через всю поверхность у твердого сплава без покрытия потребуется 57 с. В сплаве 2 с механизмом теплоотвода внутрь основы максимальная температура в точке Р2 достигла $221^{\circ} \mathrm{C}$ за 12 с и сохранялась до 27 с, а во всех остальных точках максимум температуры образовывался за 42 с. Итак, сплав 2 по всей защищаемой поверхности нагрелся на 15 с (на 27 \%) быстрее, при этом максимальная температура нагрева была на 13 \% ниже, чем у сплава 1. В данном случае быстрый нагрев способствовал быстрому остыванию, в точке P2 максимальная температура сплава 2 стала снижаться на 30 с раньше (на 53 \% быстрее), снижение началось через 27 с, при этом у сплава 1 снижение максимальной температуры началось через 57 с. Таким образом, установлено, что изменение распределения температуры на поверхности твердого сплава за счет формируемого теплоотводящего покрытия заключается в уменьшении значения температуры и увеличении скорости остывания поверхности в точке Р2 за счет отведения тепла в основу твердого сплава согласно механизму работы покрытия. 


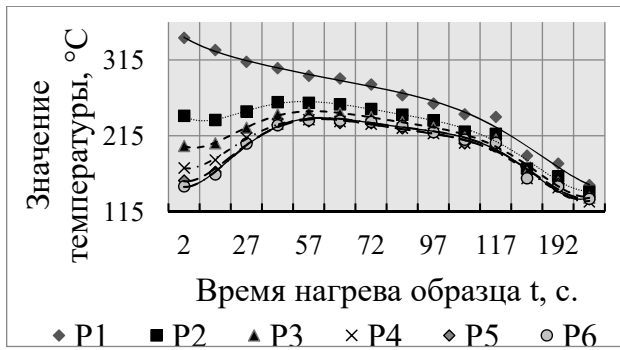

a)

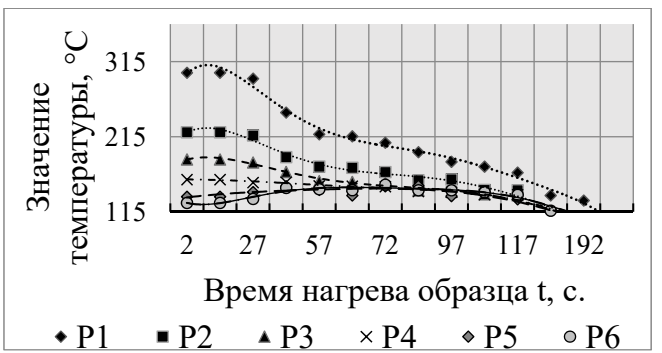

б)

Рис. 4. Исследование распределения температуры через всю поверхность твердого сплава, в точках P1-P6: а - измерения температуры поверхности сплава 1; б - измерения температуры поверхности сплава 2

Fig. 4. The study of the temperature distribution across the entire surface of the carbide, at points P1-P6: a - measuring the surface temperature of the alloy $1 ; \sigma$ - measuring the surface temperature of the alloy 2

При помощи термографа по точкам P1 - Р6 измеряли и сравнивали: время, требующееся на нагрев поверхности, температуру остывания исследуемого образца и время достижения максимальной температуры по всей поверхности твердого сплава (рис. 4).

На приведенном графике рис. 4 заметно отличие значения температур между точкой P1 и остальными точками. При этом точка P1 находится на расстоянии 0,28 мм от режущей кромки, а точка Р2 - на расстоянии 2,28 мм от края сплава - этим объясняется различие температур между точками. Такая скорость изменения температур, зависящая от расстояния, связана с более низкой теплопроводностью твердого сплава по сравнению с контртелом. Наиболее вероятно, что тепло, передаваемое от нагретого стального контртела, задерживается (накапливается) в точке контакта твердого сплава и контртела и затем постепенно передается в основу твердого сплава. Разница в значениях температур для сплава 1 (рис. $4 a$ ) между $\mathrm{P} 1$ и Р2 составляет $100{ }^{\circ} \mathrm{C}$, что способствует возникновению термомеханических напряжений и ведет к разрушению режущей кромки. Эмпирически установлено, что если отклонение значений температуры в точках P1 и Р2 больше 20 \%, то показания в остальных точках измерения температуры значительно искажаются; это ведет к необходимости повторения эксперимента с устранением факторов, влияющих на отклонения значений температуры.

Установлено, что разница температур между точкой Р1 и Р2 в сплаве 1 через 2 с после контакта с нагретым контртелом составила $103{ }^{\circ} \mathrm{C}$, но через 10 с эта разница уменьшилась на $11{ }^{\circ} \mathrm{C}$ и составила $92{ }^{\circ} \mathrm{C}$. При этом отмечается отсутствие разницы в перепадах температур у сплава 2. Так, разница между точками $\mathrm{P} 1$ и $\mathrm{P} 2$ через 2 и через 10 с составила $79^{\circ} \mathrm{C}$. Перепад температур способствует возникновению термомеханических напряжений в поверхностном слое инструментального материала из твердого сплава. Под действием таких напряжений при обработке полимерных материалов период стойкости твердосплавного инструмента значительно снижается. Работа покрытия заключается в отводе тепла из зоны нагрева твердого сплава, таким образом снижается перепад температур и уменьшается вероятность возникновения напряжений в поверхностном слое.

Изменение скорости распространения температуры по всей поверхности твердого сплава в зависимости от покрытия определялось временем ее максимума в каждой измеряемой точке. В ходе исследования нас интересовало распространение тепла через все покрытие от точки Р2 
до точки Р5, а также распространение тепла по участку после покрытия. При этом подтверждение механизма работы покрытия отражается в точке 6 ниже покрытия в виде снижения температуры, в то время как у сплава 1 в этой точке температура будет изменяться одинаково со всей поверхностью. Температура в точке Р6 не возросла, как в других сплавах, что указывает на вывод теплоты в основу твердого сплава. Элементный состав покрытия на сплаве 2 показал наличие хрома, который в соединении с другими металлами обладает более низкой теплопроводностью по сравнению с твердыми сплавами. В связи с этим предполагается, что покрытие обладает теплосопротивлением, это способствует отражению тепловой энергии в материал, где теплопроводность выше. Для подтверждения отвода тепла из зоны нагрева проводили визуальное исследование распределения тепловых полей (рис. 5).

На рис. 5a, б представлены: нагретое контртело (сверху), твердый сплав (снизу) без покрытия (сплав 1) и твердый сплав с покрытием из комбинации анодных материалов - медь, никель, белый чугун с добавкой хрома и вольфрама (сплав 2). Съемка термограммы проводилась через 60 с после контакта нагретого контртела и твердого сплава. Выбор данного времени обусловлен тем, что за 60 с достигается максимальная температура на всей исследуемой поверхности твердого сплава без покрытия. Сравнение двух изображений на рис. $5 a$, $б$ показывает совпадающие условия передачи температуры от контртела к твердому сплаву. Механизм работы покрытия в виде отвода тепла от поверхности в основу на сплаве 2 подтверждается исследованием изменения температуры (рис. 56, г) в точках перед покрытием
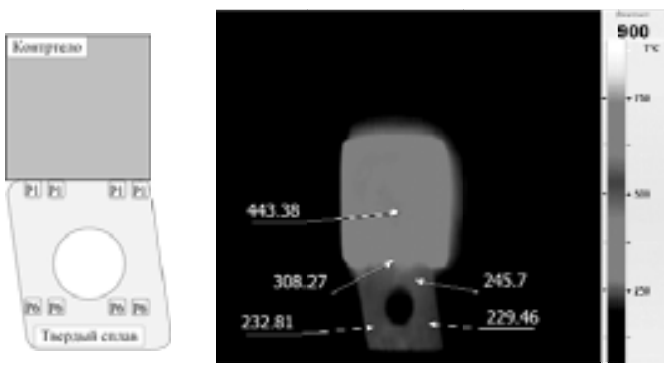

а) сплав 1

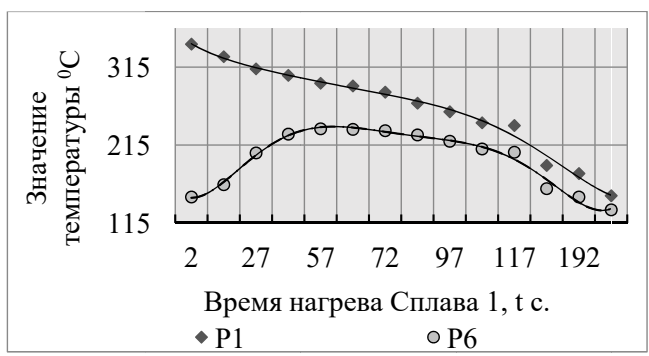

в) сплав 1
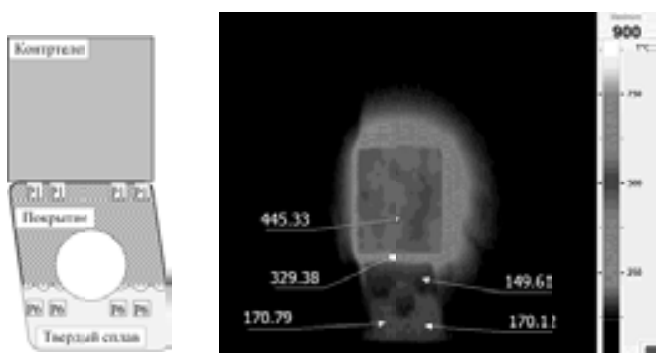

б) сплав 2

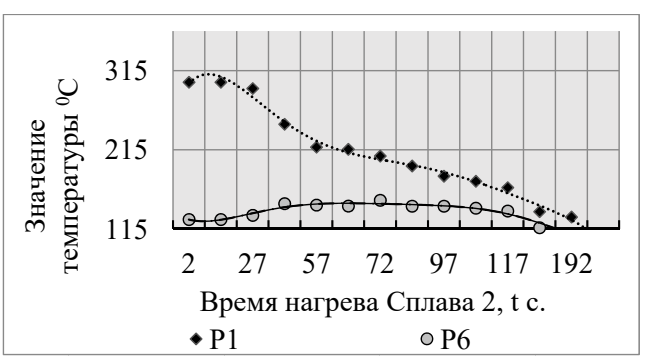

г) сплав 2

Рис. 5. Распределение температуры на поверхности твердого сплава (вид сверху): а, б - термограмма распределения тепловых полей за 60 c; в, г- измерения температуры в точках контакта с контртелом (P1) и ниже покрытия (P6)

Fig. 5. Temperature distribution on the surface of the carbide (top view): a, $\sigma-a$ thermogram of the distribution of thermal fields in 60 seconds; $\mathrm{B}, \Gamma-$ temperature measurements at points of contact with the counterbody (P1) and below the cover (P6) 
(P1) и после покрытия (Р6). Для сплава 1 без покрытия характерно равномерное изменение температуры с ее уменьшением по мере удаления от источника нагрева, покрытие на сплаве 2 способствует отражению тепла во внутрь твердого сплава, поэтому в начальный момент времени контакта с нагретым контртелом наблюдается меньшее значение температуры, а затем резкое ее снижение по сравнению со сплавом 1. Сравнения температур в точке Р6 показывают нагрев на $100{ }^{\circ} \mathrm{C}$ меньше для сплава 2 в точке контакта с контртелом и на $50{ }^{\circ} \mathrm{C}$ меньше в точке ниже участка с покрытием. При одинаковых условиях проведения эксперимента наиболее вероятно, что передаваемое тепло отражается от покрытия в основу твердого сплава. Таким образом, доказан и подтвержден механизм теплоотвода у покрытия при контакте с нагретым контртелом. Исследование микроструктуры покрытия после его контакта с источником тепла и выдержки до полного остывания показало, что микротрещины не появляются, структура остается сплошной, без видимых дефектов.

\section{Заключение}

Анализ элементного состава покрытия сплава 2 выявил наличие хрома в количестве $8,73 \%$, который в соединении с металлами $\mathrm{Fe}, \mathrm{Ni}$ и др. обладает более низкой теплопроводностью по сравнению с твердыми сплавами, что способствует отражению тепловой энергии в материал, где теплопроводность выше. Это определяет механизм теплоотвода в основу защищаемого материала и снижает максимальную температуру нагрева на всей поверхности режущего инструмента.

Тепловизионные исследования показали неравномерное распределение температурных полей у подложки ВК8 с многослойным покрытием по сравнению с подложкой без покрытия. Многослойное покрытие, содержащее в себе $\mathrm{Ni}, \mathrm{Cu}, \mathrm{Fe}, \mathrm{Cr}, \mathrm{W}$, по сравнению с подложкой ВК8 без покрытия остывает в 2 раза быстрее и нагревается в точке контакта с контртелом на $40 \%$ ниже, при этом температура от места нагрева распространяется по всей подложке, не накапливаясь в режущей кромке.

\section{Список литературы / References}

[1] Востриков Я.А., Верхотуров А.Д., Рыбалкин А.А., Гнатик А.О. Повышение эффективности формирования легированного слоя при упрочнении вольфрамсодержащих твердых сплавов комбинированными методами. Ученые записки Комсомольского-на-Амуре государственного технического университета. Науки о природе и технике, 2016, IV, 1(28), 78-87 [Vostrikov I.A., Verkhoturov A.D., Rybalkin A.A., Gnatik A.O. Improving the efficiency of forming a doped layer during hardening of tungsten-containing hard alloys by combined methods. Scientific notes Komsomolsk-on-Amur State Technical University. Science of nature and technology, 2016, IV, 1(28), 78-87 (in Russian)]

[2] Куликов М.Ю., Попов А.Ю., Флоров А.В., Сан Маунг. Пути снижения теплонапряженности режущего клина при колесотокарной обработке. Известия высших учебных заведений. Поволжский регион. Технические науки, 2014, 4(32), 192-199 [Kulikov M.Yu., Popov A.Yu., Florov A.V., San Maung. Ways to reduce the thermal stress of a cutting wedge during wheel turning. News of higher educational institutions. Volga region. Technical science, 2014, 4 (32), 192-199 (in Russian)] 
[3] Wang B., Gao H., Cao B., Zhuang Y., \& Zhao Z. Mechanism of damage generation during drilling of carbon/epoxy composites and titanium alloy stacks. Proceedings of the Institution of Mechanical Engineers, Part B. Journal of Engineering Manufacture, 2014, 228(7), 698-706.

[4] Гайст С.В., Марков А.М., Черданцев П.О., Катаева С.А., Лапенков Е.Ю. Исследование температуры при фрезеровании стеклопластика. Актуальные проблемы в машиностроении, 2016, 3, 123-128 [Gaist S.V., Markov A.M., Cherdantsev P.O., Kataeva S.A., Lapenkov E.Yu. Study of temperature during fiberglass milling. Actual problems in mechanical engineering, 2016, 3, 123-128 (in Russian)] 